\title{
Estimates of genetic parameters and genetic trends for reproductive traits and weaning weight in Tabapuã cattle ${ }^{1,2}$
}

\author{
P. A. Bernardes, * D. A. Grossi, * R. P. Savegnago, * \\ M. E. Buzanskas, * I. Urbinati, * L. A. F. Bezerra, $†$ R. B. Lôbo, \\ *Departamento de Ciências Exatas, Faculdade de Ciências Agrárias e Veterinárias, Universidade \\ Estadual Paulista, Jaboticabal, São Paulo, Brazil; † Departamento de Genética, FMRP/USP, Ribeirão Preto, \\ São Paulo, Brazil; and \$ANCP National Breeders’ and Researchers’ Association, Ribeirão Preto, São Paulo, Brazil
}

\begin{abstract}
The Tabapuã breed is a beef cattle Brazilian breed known for its sexual precocity and desirable characteristics for tropical conditions. However, this is a newly formed breed and few studies have been conducted regarding genetic parameters and genetic trends for its reproductive traits. The objective of the present study was to estimate the genetic parameters, genetic trends, and relative selection efficiency for weaning weight adjusted to $210 \mathrm{~d}$ of age (W210), age at first calving (AFC), average calving interval (ACI), first calving interval (CI1), and accumulated productivity (ACP) among Tabapuã beef cattle. Pedigree data on 15,241 Tabapuã animals born between 1958 and 2011 and phenotype records from 7,340 cows born between 1970 and 2011 were supplied by the National Association of Breeders and Researchers (Associação Nacional de Criadores e Pesquisadores). Analysis through the least squares method assisted in defining the fixed effects that were considered within the models. The estimates for the
\end{abstract}

genetic parameters were obtained through the REML, using a multitrait animal model. The likelihood ratio test applied for W210 was significant $(P<0.05)$ for the inclusion of maternal additive genetic and permanent environmental effects in the model. Genetic trends were calculated through linear regression of the EBV of the animals, according to the year of birth. The heritability estimates obtained ranged from $0.04 \pm$ 0.03 for CI1 to $0.25 \pm 0.05$ for W210. The genetic correlations ranged from $0.004 \pm 0.19$ for W210-AFC and $0.93 \pm 0.12$ for ACI-CI1. The genetic trend was significant $(P<0.05)$ and favorable for CI1 and the maternal genetic effect of $\mathrm{W} 210$ and was significant $(P<0.05)$ and unfavorable for AFC, ACI, and ACP. The ACP could be used in the selection index to assist the breeding goal of improved productive and reproductive performance. The genetic trends indicated small and unfavorable genetic changes for AFC, ACI, and ACP in light of the recent implementation of a genetic breeding program for this breed.

Key words: accumulated productivity, age at first calving, bovine, calving interval, genetic correlation, heritability

(C) 2015 American Society of Animal Science. All rights reserved. J. Anim. Sci. 2015.93:5175-5185 doi:10.2527/jas2015-9212

\footnotetext{
${ }^{1}$ The authors report that there are no conflicts of interest relevant to this publication.

${ }^{2}$ We thank the ANCP - National Breeders' and Researchers' Association for providing the data set used in this study. P. A. Bernardes and I. Urbinati received scholarships from the São Paulo Research Foundation (Fundação de Amparo à Pesquisa do Estado de São Paulo -FAPESP - process numbers 2013/09364-5 and 2013/09050-0, respectively) and from the National Council for Scientific and Technological
}

Development (Conselho Nacional de Desenvolvimento Científico e Tecnológico). R. P. Savegnago and M. E. Buzanskas received postdoctoral fellowship from the FAPESP (fellowship numbers 2013/20091-0 and 2013/19335-2). D. P. Munari held productivity research fellowship from CNPq (fellowship number 306336/2011-1).

${ }^{3}$ Corresponding author: danisio@fcav.unesp.br

Received April 15, 2015.

Accepted September 16, 2015. 


\section{INTRODUCTION}

The Tabapuã breed was originating by crossing breeds such as the Brazilian polled cattle, Gir, Guzerá, and Nelore (Silva Filho et al., 2012). The goal of the breeding program for this breed is improve productive and reproductive performance. The selection criterion recommended to attain this goal is an index called Total Genetic Merit (MGT), which includes maternal and direct genetic effect on weight at $120 \mathrm{~d}$ of age, direct genetic effect on weights and scrotal circumferences at 365 and $450 \mathrm{~d}$ of age, and age at first calving.

Weights measured early in animal life, such as weaning weight, are used as a selection criteria in genetic breeding programs because they have a high and positive genetic correlation with weights at future ages (Ferraz Filho et al., 2002). The reproductive traits of females have economic importance because cows that calve early and that have regular calving intervals produce more calves in less time, consequently increasing the replacement rate of females and the productivity of the farm (Aby et al., 2012). Therefore, productive and reproductive traits need to be evaluated for consideration as selection criteria according to breeding goal.

Accumulated productivity is an index that combines productive and reproductive performance and takes into consideration sexual precocity, fertility, and maternal ability to wean heavier calves. The heritability estimates of this index demonstrate that it can respond well to selection (Rosa, 1999).

Given that the Tabapuã breed had official recognition only in 1981, there are few studies in the literature with estimates for genetic parameters for this breed (Guimarães et al., 2003; Pereira et al., 2005). Therefore, the objectives of the present study were to estimate genetic parameters and genetic trends for productive and reproductive traits and to evaluate the relative efficiency of selection for traits of lower heritability to indicate which traits would be more appropriate for inclusion as selection criteria among animals.

\section{MATERIAL AND METHODS}

\section{Description of Data}

The data used in the present study were obtained through the Genetic Breeding Program for the Tabapuã Breed (Programa de Melhoramento Genético da Raça Tabapuã [PMGRT]), maintained by the National Association of Breeders and Researchers (Associação Nacional de Criadores e Pesquisadores). The animals belonged to farms in 8 Brazilian states: São Paulo, Bahia, Minas Gerais, Mato Grosso, Mato Grosso do Sul, Goiás, Tocantins, and Paraná. They were raised on pasture and weaned between the ages of 6 and 8 mo. The reproductive management consisted of using a mating season of 60 to $120 \mathrm{~d}$, using either artificial insemination or natural controlled breeding.

The phenotype records of 7,340 cows, born between 1970 and 2011, and a pedigree file of 15,241 animals of the Tabapuã breed, born between 1958 and 2011, were used in the present study. The traits used were weaning weight adjusted to $210 \mathrm{~d}$ of age (W210) in kilograms, age at first calving (AFC) in months, first calving interval (CI1) in days, average calving interval (ACI) in days, and accumulated productivity (ACP) in kilograms weaning calves per dam per year.

Accumulated productivity provides the weight in kilograms of weaned calves per female, which is related to the AFC, calving intervals, and weaning weight (Schwengber et al., 2001). This parameter was calculated using the formula $\mathrm{ACP}=\left(W_{w} n p^{365}\right) /\left(A C C_{n}-550\right)$, in which $W_{w}$ is the mean weight of weaned calves, standardized as $210 \mathrm{~d}$ of age; $n_{p}$ is the total number of calves produced; 365 is a constant equal to $365 \mathrm{~d}$ that allows fertility to be expressed on an annual basis; $\mathrm{ACC}_{n}$ is the age of the cow (in days) at the last calving; and 550 is a constant equal to $550 \mathrm{~d}$, considering that the goal of the PMGRT for the AFC is 30 mo (Lôbo et al., 2000), with a minimum breeding age of $18 \mathrm{mo}$.

Preliminary analyses were conducted to eliminate inconsistent data from the file. For AFC, females were kept if their first birth was between 21 and 48 mo of age, considering that the upper limit is the one adopted by the PMGRT to exclude the records that should be considered in the analysis. The minimum limit adopted for considering the records for the ACI and CI1 traits was $348 \mathrm{~d}$, obtained by summing the minimum period of 60 $\mathrm{d}$ to return to heat under normal postpartum conditions (Henao et al., 2000) and a mean gestation period of $288 \mathrm{~d}$ for Tabapuã breed (ANCP, 2014). The maximum limit considered for ACI and CI1 was $793 \mathrm{~d}$; it is equal to 5 mo corresponding to the return to estrus, plus 12 mo between the end of the return to estrus and the next breeding season, plus 9 mo corresponding to the second gestation length, totaling $26 \mathrm{mo}$ (793 d).

\section{Data Analysis}

The fixed effects considered in the animal model were defined through the least squares method, using the GLM routine of the SAS software (SAS 9.2; SAS Inst. Inc., Cary, NC). The effects of farm, year, and season (trimester) of birth were tested when forming contemporary groups $(\mathbf{C G})$ for all the traits. All the effects were significant $(P<0.05)$ for W210. For AFC, ACI, CI1, and ACP, only the effects of the farm and year of birth were significant $(P<0.05)$ and considered on $C G$. 
Contemporary groups with fewer than 3 animals were excluded from the analyses (Table 1) and observations with standardized residuals greater or lower than 3.5 were excluded from the final data set. Moreover, the degree of connection between the CG was assessed through the AMC software (Roso and Schenkel, 2006). Only related groups were kept in the analysis.

The covariable of age of cow at calving presented a linear and quadratic effect $(P<0.05)$ for W210, and the covariable AFC presented a linear and quadratic effect $(P<0.05)$ for CI1.

\section{Estimates of Genetic Parameters}

The estimates of the variance components and the genetic parameters were obtained through the REML method, through a multitrait animal model using WOMBAT software (Meyer, 2007). The convergence criterion adopted was $10^{-9}$. Two multitrait analyses were performed: first using W210, AFC, ACI, and CI1 and second using AFC, ACP, ACI, and CI1. This division into 2 analyses was made because of the nonconvergence of the analyses using W210 and ACP simultaneously. This may have been due to the small number of animals that presented phenotype values for these 2 traits. Moreover, W210 is a component in the calculation of ACP, which could have made it more difficult to estimate the variance components of these traits.

The general model used in the multitrait analysis was $\boldsymbol{y}=\boldsymbol{X} \boldsymbol{b}+\boldsymbol{Z} \boldsymbol{a}+\boldsymbol{e}$, in which $\boldsymbol{y}$ is the vector with the phenotype records, $\boldsymbol{b}$ is the vector with the solution for the fixed effects, $\boldsymbol{a}$ is the vector of the solutions for the random additive genetic effect, $\boldsymbol{e}$ is the vector for the random residuals, and $\mathrm{X}$ and $\mathrm{Z}$ are the incidence matrices associated with $\mathrm{b}$ and $\mathrm{a}$, respectively.

The general structure of variance and covariance of the random effects in the models was

$$
\left[\begin{array}{l}
\mathbf{a} \\
\mathbf{e}
\end{array}\right] \sim N(0, \mathbf{V}) ; \mathbf{V}=\left[\begin{array}{cc}
\mathbf{G} \otimes \mathbf{A} & 0 \\
0 & \mathbf{R} \otimes \mathbf{I}
\end{array}\right],
$$

in which $\mathbf{G}$ is the variance-covariance matrix of the direct additive genetic effects, $\boldsymbol{A}$ is the kinship matrix, $\boldsymbol{R}$ is the residual variance-covariance matrix, $\boldsymbol{I}$ is the identity matrix, and $\otimes$ is the direct product of the matrices.

\section{Likelihood Ratio Test}

The models for each trait were defined through previous analyses using a single-trait animal model. For W210, the single-trait analyses were performed by applying 4 different models:

$$
\text { Model 1: } y=X b+Z_{1} a+e,
$$

Table 1. Number of animals, sires, dams, contemporary group (CG) with farms, years, and season, mean, $\mathrm{SD}$, minimum and maximum values, and $\mathrm{CV}$ for traits studied among Tabapuã beef cattle

\begin{tabular}{lrrrrr}
\hline \hline Trait & $\mathrm{W} 210^{1}$ & \multicolumn{1}{c}{$\mathrm{AFC}^{2}$} & \multicolumn{1}{c}{$\mathrm{ACI}^{3}$} & \multicolumn{1}{c}{$\mathrm{CI}^{4}$} & \multicolumn{1}{c}{$\mathrm{ACP}^{5}$} \\
\hline Animal & $2,943.00$ & $5,019.00$ & $2,536.00$ & $2,540.00$ & $1,030.00$ \\
Sire & 299.00 & 530.00 & 402.00 & 403.00 & 235.00 \\
Dam & $2,170.00$ & $3,445.00$ & $1,949.00$ & $1,951.00$ & 893.00 \\
CG & 141.00 & 201.00 & 156.00 & 157.00 & 65.00 \\
Farms & 9.00 & 13.00 & 13.00 & 13.00 & 7.00 \\
Years & 22.00 & 36.00 & 35.00 & 35.00 & 15.00 \\
Season & 4.00 & - & - & - & - \\
Mean & 178.82 & 37.44 & 505.24 & 524.46 & 144.67 \\
SD & 25.98 & 5.51 & 96.26 & 120.41 & 28.23 \\
Minimum & 86.00 & 21.00 & 348.00 & 348.00 & 48.00 \\
Maximum & 272.00 & 48.00 & 789.00 & 792.00 & 219.00 \\
CV, \% & 14.53 & 14.71 & 19.05 & 22.96 & 19.52 \\
\hline
\end{tabular}

${ }^{1} \mathrm{~W} 210=$ weaning weight adjusted to $210 \mathrm{~d}$ of age $(\mathrm{kg})$.

${ }^{2} \mathrm{AFC}=$ age at first calving (mo).

${ }^{3} \mathrm{ACI}=$ average calving interval $(\mathrm{d})$.

${ }^{4} \mathrm{CI} 1=$ first calving interval $(\mathrm{d})$.

${ }^{5} \mathrm{ACP}=$ accumulated productivity ( $\mathrm{kg}$ weaning calves per dam per year.

Model 2: $y=X b+Z_{1} a+Z_{2} m+e$,

Model 3: $y=X b+Z_{1} a+W_{c}+e$, and

Model 4: $y=X b+Z_{1} a+Z_{2} m+W_{c}+e$,

in which $\boldsymbol{y}$ is the observations vector; $\boldsymbol{b}$ is the vector for fixed effects; $\boldsymbol{a}, \boldsymbol{m}$, and $\boldsymbol{c}$ are vectors for the direct additive genetic, the maternal genetic, and the maternal permanent environment random effects; $\boldsymbol{e}$ is the vector for residual effects; and $\boldsymbol{X}, \boldsymbol{Z}_{\mathbf{1}}, \boldsymbol{Z}_{2}$, and $\boldsymbol{W}$ are incidence matrices for $b, a, m$, and $c$, respectively.

The likelihood ratio test was used to evaluate the differences between models. The test indicates whether there were any significant differences $(P<0.05)$ between the likelihood of the null model (fewer parameters) and the likelihood of the alternative model (more parameters). The value of the test (D) is compared with the values of a $\chi^{2}$ distribution, with the same number of degrees of freedom as in the difference in the number of parameters between the alternative and null models (Dobson, 1990). The inclusion of maternal genetic effect and the inclusion of maternal permanent environment effect in the simple model were tested comparing model 2 with model 1 and model 3 with model 1 , respectively. The significance of both maternal genetic and maternal permanent environment effects at the same time (model 4) was tested comparing the full model (model 4) with model 2 (with maternal genetic 
effect and without maternal permanent environment effect) and with model 3 (without maternal genetic effect and with maternal permanent environment effect), using $\mathrm{df}=1$. For AFC, the maternal random genetic effects and the permanent environmental effects were not tested, as seen in other studies (Buzanskas et al., 2010; Laureano et al., 2011; Boligon et al., 2012), because the influence of these components is observed mainly until weaning (Boligon et al., 2010). The inclusion of the maternal random genetic effect and the permanent environmental effect in the model was also not evaluated for the remaining traits, because the structure of the data set and the pedigree records was not sufficient to estimate them.

\section{Relative Selection Efficiency}

The relative selection efficiency was calculated for traits that presented low heritability magnitude and high genetic correlation with another trait with higher heritability magnitude. According to Bourdon (2000), relative selection efficiency is calculated as $C R_{x} / R_{x}=r_{a} r_{y} i_{y} /$ $r_{x} i_{x}$, in which $C R_{x}$ is the response correlated with the main trait $(x)$ when the selection was applied to the secondary trait $(y), R x$ is the response to direct selection of the main trait $(x), r_{a}$ is the genetic correlation between traits $x$ and $y, r_{y}$ is the accuracy for secondary trait $(y)$, $r_{x}$ is the accuracy for the main trait $(x), i_{y}$ is the selection intensity applied to the secondary trait $(y)$, and $i_{x}$ is the intensity of selection applied to the main trait $(x)$.

Considering that the intensity of selection applied to both traits was the same, because the traits were measured only among females, $i_{y}=i_{x}=i$; therefore, $C R_{x} / R_{x}=r_{a} r_{y} / r_{x}$.

This expression makes it possible to evaluate whether indirect selection would be better than direct selection, that is, when the numerator $\left(r_{a} r_{y}\right)$ is greater than the denominator $\left(r_{x}\right)$.

\section{Genetic Trends}

The genetic trends were calculated through linear regression of the EBV for the animals, which presented accuracy of at least 0.4 , according to the year of birth, for the period from 1981 to 2009 . The regression coefficient for the genetic trends was tested using $t$ statistics considering the hypothesis of nullity, in which the regression coefficient does not differ from $0(P=0.05)$.

\section{RESULTS AND DISCUSSION}

\section{Data Description}

The mean observed for W210 (Table 1) was higher than those obtained by other authors (ranging from 167.71 to $175.91 \mathrm{~kg}$ ) for the same breed, (Guimarães et al., 2003; Sakaguti et al., 2003; Ribeiro et al., 2007; Ventura et al., 2012; Campos, 2013) and lower than the mean obtained by Silva Filho et al. (2013), which was $212.4 \mathrm{~kg}$. The mean AFC obtained in the present study was similar to that found by Pereira et al. (2005) for the same breed and similar to the values obtained for the Nelore, Gir, and Guzerá breeds (Grossi et al., 2009; Panetto et al., 2010; Santana Júnior et al., 2010; Boligon and Albuquerque, 2011; Barrozo et al., 2012).

The difference in the means for ACI and CI1 (Table 1) was expected, due to the energy demands for lactation, growth, and persistence of the estrous cycle of the animals that gave birth for the first time (Cunningham, 2007). The mean for CI1 was similar to that obtained by Pereira et al. (2005) for Tabapuã cattle and lower than the means obtained for the Nelore and Guzerá breeds (Paneto et al., 2008; Panetto et al., 2010; Yokoo et al., 2012). The mean for ACP was similar to that obtained by Rosa (1999), lower than that observed by Grossi et al. (2008), and higher than the values obtained by Schwengber et al. (2001) and Azevêdo et al. (2005) of $130 \pm 35$ and $96.74 \pm 46.7 \mathrm{~kg}$ of calves per dam per year, respectively, for Nelore cattle.

\section{Genetic Parameter Estimates}

The heritability estimates for W210 (Table 2) were intermediate to those found in the literature for Tabapuã cattle, which ranged from $0.14 \pm 0.05$ to $0.41 \pm 0.04$ for direct heritability and from $0.06 \pm 0.08$ to 0.17 for maternal heritability (Ferraz Filho et al., 2002; Guimarães et al., 2003; Ribeiro et al., 2007; Campos, 2013; Silva Filho et al., 2013). These estimates suggest that the proportion of phenotype variation that is attributed to the additive effects of the genes allows a response to the selection process. The importance of the maternal genetic effect and the permanent environmental effect in estimating the genetic parameters for W210 becomes evident through observing that the sum of the variance of the 2 parameters results in a value that is close to the value of the additive genetic variance.

The heritability estimates for the reproductive traits (AFC, ACI, and CI1) were of low magnitude (Table 2). Low heritability was found for calving interval in beef cattle by Berry and Evans (2014). Pereira et al. (2005) reported estimates of 0.03 for AFC and 0.01 for CI1 among Tabapuã cattle. The estimates found in the literature for the reproductive traits in this breed were lower because these studies used data sets comprising only 1 farm, in which the heifers were either mated or inseminated when they reached $310 \mathrm{~kg}$, which made it difficult to identify females that were more precocious.

Although the heritability estimates for the reproductive traits were of low magnitude (Table 2), a study 
Table 2. Estimates of direct $\left(h_{a}{ }^{2}\right)$ and maternal $\left(h_{m}{ }^{2}\right)$ heritability, proportion of maternal permanent environmental variance to total variance $\left(c^{2}\right)$, components of direct genetic variance $\left(\boldsymbol{\sigma}_{a}^{2}\right)$, residual variance $\left(\boldsymbol{\sigma}_{e}{ }^{2}\right)$, maternal genetic variance $\left(\boldsymbol{\sigma}_{m}{ }^{2}\right)$, and permanent environment variance $\left(\boldsymbol{\sigma}_{c}{ }^{2}\right)$ and their respective SE for traits studied among Tabapuã cattle

\begin{tabular}{|c|c|c|c|c|c|c|c|}
\hline \multicolumn{8}{|c|}{ A. Multitrait 1} \\
\hline Trait $^{1}$ & $h_{a}^{2}$ & $h_{m}^{2}$ & $c^{2}$ & $\sigma_{a}^{2}$ & $\sigma_{e}^{2}$ & $\sigma_{m}^{2}$ & $\sigma_{c}^{2}$ \\
\hline W210 & $\begin{array}{c}0.25 \\
(0.05)\end{array}$ & $\begin{array}{c}0.10 \\
(0.04)\end{array}$ & $\begin{array}{c}0.10 \\
(0.04)\end{array}$ & $\begin{array}{l}114.17 \\
(24.98)\end{array}$ & $\begin{array}{l}250.31 \\
(20.24)\end{array}$ & $\begin{array}{c}43.27 \\
(16.27)\end{array}$ & $\begin{array}{c}45.33 \\
(18.24)\end{array}$ \\
\hline $\mathrm{AFC}$ & $\begin{array}{c}0.09 \\
(0.02)\end{array}$ & - & - & $\begin{array}{c}1.88 \\
(0.51)\end{array}$ & $\begin{array}{l}18.92 \\
(0.58)\end{array}$ & - & - \\
\hline ACI & $\begin{array}{c}0.06 \\
(0.04)\end{array}$ & - & - & $\begin{array}{c}416.76 \\
(282.89)\end{array}$ & $\begin{array}{l}7,200.62 \\
(334.02)\end{array}$ & - & - \\
\hline CI1 & $\begin{array}{c}0.04 \\
(0.03) \\
\end{array}$ & - & - & $\begin{array}{r}502.96 \\
(389.99) \\
\end{array}$ & $\begin{array}{l}12,093.40 \\
(501.11)\end{array}$ & - & - \\
\hline \multicolumn{8}{|c|}{ B. Multitrait 2} \\
\hline Trait & $h_{a}^{2}$ & $\mathrm{~h}_{\mathrm{m}}{ }^{2}$ & $\mathrm{c}^{2}$ & $\sigma_{\mathrm{a}}^{2}$ & $\sigma_{\mathrm{e}}^{2}$ & $\sigma_{\mathrm{m}}^{2}$ & $\sigma_{\mathrm{c}}^{2}$ \\
\hline $\mathrm{AFC}$ & $\begin{array}{c}0.09 \\
(0.02)\end{array}$ & - & - & $\begin{array}{c}1.82 \\
(0.51)\end{array}$ & $\begin{array}{l}18.94 \\
(0.58)\end{array}$ & - & - \\
\hline $\mathrm{ACP}$ & $\begin{array}{c}0.18 \\
(0.06)\end{array}$ & - & - & $\begin{array}{l}102.15 \\
(36.62)\end{array}$ & $\begin{array}{l}472.05 \\
(37.62)\end{array}$ & - & - \\
\hline ACI & $\begin{array}{c}0.08 \\
(0.04)\end{array}$ & - & - & $\begin{array}{c}582.47 \\
(287.80)\end{array}$ & $\begin{array}{r}7,108.83 \\
(330.47)\end{array}$ & - & - \\
\hline CI1 & $\begin{array}{c}0.05 \\
(0.03)\end{array}$ & - & - & $\begin{array}{c}632.53 \\
(393.23)\end{array}$ & $\begin{array}{l}12,053.10 \\
(498.25)\end{array}$ & - & - \\
\hline
\end{tabular}

${ }^{1} \mathrm{~W} 210=$ weaning weight adjusted to $210 \mathrm{~d}$ of age $(\mathrm{kg}) ; \mathrm{AFC}=$ age at first calving (mo); $\mathrm{ACI}=$ average calving interval (d); CI1 = first calving interval (d); $\mathrm{ACP}=$ accumulated productivity ( $\mathrm{kg}$ weaning calves per dam per year).

performed by Aby et al. (2012) indicated that these traits are economically important in production systems and that small but constant genetic changes can promote economic gains for the producer. Moreover, selection for reproductive traits favors a decrease in the interval of generations and can increase the annual genetic gain of selected traits.

The heritability estimate for ACP (Table 2) was similar to that obtained by Schwengber et al. (2001) and is among the estimates observed in other studies on Nelore cattle (Azevêdo et al., 2005; Faria et al., 2007; Grossi et al., 2008; Chud et al., 2014). Although the results found in the literature regarding heritability estimates for ACP were varied, the ACP heritability in the present study presented moderate magnitude and, therefore, could respond favorably to the selection process. Use of ACP in selection programs can be advantageous when used as a substitute for low heritability traits or measurements made later in the animal's life, such as stayability, which requires more calvings than ACP to be calculated (Schwengber et al., 2001; Grossi et al., 2008; Chud et al., 2014).

The genetic correlation close to 0 between W210 and AFC and the low genetic association between W210 and CI1 (Table 3) indicated that selection of
Table 3. Estimates of genetic correlations (above diagonal) and environmental correlations (below diagonal) and their respective SE for traits studied among Tabapuã cattle

\begin{tabular}{lcccc}
\hline \hline \multicolumn{5}{c}{ Multitrait 1 } \\
\hline Trait $^{1}$ & W210 & AFC & ACI & CI1 \\
\hline W210 & - & $0.004(0.19)$ & $0.45(0.33)$ & $0.08(0.35)$ \\
AFC & $-0.37(0.05)$ & - & $0.70(0.34)$ & $0.90(0.39)$ \\
ACI & $-0.08(0.07)$ & $-0.09(0.03)$ & - & $0.90(0.16)$ \\
CI1 & $-0.13(0.07)$ & $-0.15(0.03)$ & $0.75(0.01)$ & - \\
\hline \multicolumn{5}{c}{ Multitrait 2 } \\
\hline Trait & AFC & ACP & ACI & CI1 \\
\hline AFC & - & $-0.60(0.18)$ & $0.74(0.28)$ & $0.92(0.33)$ \\
ACP & $-0.34(0.04)$ & - & $-0.83(0.20)$ & $-0.84(0.28)$ \\
ACI & $-0.11(0.03)$ & $-0.57(0.04)$ & - & $0.93(0.12)$ \\
CI1 & $-0.16(0.03)$ & $-0.44(0.04)$ & $0.75(0.01)$ & - \\
\hline
\end{tabular}

${ }^{1} \mathrm{~W} 210=$ weaning weight adjusted to $210 \mathrm{~d}$ of age $(\mathrm{kg}) ; \mathrm{AFC}=$ age at first calving (mo); $\mathrm{ACI}=$ average calving interval (d); CI1 = first calving interval (d); $\mathrm{ACP}=$ accumulated productivity ( $\mathrm{kg}$ weaning calves per dam per year).

animals based on W210 would not result in genetic changes in AFC and CI1. Segura-Correa et al. (2012) observed low genetic correlation between these same traits. Boligon et al. (2010) and Laureano et al. (2011) reported genetic correlation estimates of -0.20 and -0.16 , respectively, among Nelore cattle.

The high SE of the genetic correlation estimates between W210 and ACI and between W210 and CI1 (Table 3) make it difficult to correctly evaluate the genetic association of these estimates. The genetic correlation between W210 and ACI obtained in the present study was different from that reported in a study performed by Gutiérrez et al. (2007), who observed a genetic correlation of -0.07 for the same traits among Asturiana de los Valles breed cattle. This difference may have occurred due to population or breeds differences. The animals were chosen based on their W210 resulting in higher ACI, which was expected due to the genetic correlation of $0.45 \pm 0.33$ (Table 3). This choice, based on W210, promotes large weights for adult animals that, consequently, demands more energy for maintenance and to return to estrus. Animals with high body mass tend to have high body scores, and the influence of this parameter on the mating season, in relation to ACI, was observed by Renquist et al. (2006), who reported a quadratic effect between the body score and the mating season and ACI.

The genetic correlations between AFC and ACI and between AFC and CI1 were high and positive (Table 3), therefore indicating the existence of genes in common that influenced both traits. Therefore, genetic breeding programs that have a selection objective of decreasing AFC could obtain favorable genetic gains for ACI and CI1 and, consequently, increase the productivity of the cows in the herd. High and posi- 
tive genetic correlation estimates for these traits were also observed by Vergara et al. (2009) in a multibreed population of cattle and by Gutiérrez et al. (2002) in Asturiana de los Valles beef cattle.

The genetic correlation estimates between ACP and the reproductive traits (AFC, ACI, and CI1) were high and negative (Table 3 ), therefore indicating that selection of animals based on ACP could result in genetic gains favorable toward the other traits. Although AFC is not directly a part of the formula to calculate ACP, there is a relationship between the 2 : when the cow's reproductive life is started early on, its age at the last birth is lower. This is a component of the denominator in the formula for ACP. Therefore, higher values are observed for ACP in this situation, meaning that precocious cows produce more kilograms of weaned calves. Grossi et al. (2008) found genetic correlation estimates between AFC and ACP equal to -0.71 among Nelore cattle. Eler et al. (2014) observed a similar genetic correlation between AFC and an index similar to $\mathrm{ACP}$ and observed genetic correlation of close to 1 between that index and stayability, therefore concluding that use of these indexes that allow records to be collected from younger animals can achieve genetic values of greater accuracy for these animals.

\section{Relative Selection Efficiency}

The results from the genetic correlations (Table 3) were used to calculate the relative selection efficiency between AFC and CI1, between ACP and ACI, and between $\mathrm{ACP}$ and CI1. These traits were chosen because the MGT index includes BW to improve productive precocity and includes scrotal circumference and AFC to improve reproductive precocity, which attain the breeding goal of program. However, the production of more numbers of calves and more heavy weaned calves in less time, using calving intervals and ACP as indirect or direct selection criteria, can contribute to attain the breeding goal. Besides, AFC presented higher $h^{2}$ estimates than CI1 and both presented a high genetic correlation and also because ACP presented higher $h^{2}$ estimates than ACI and CI1 and a negative genetic correlation with both of them.

The accuracies used were the average accuracies of EBV for the animal group that compound the selection path of sire to cow and the average accuracies for animals that compound the selection path group of dam to cow. For all the traits used in relative selection efficiency, the average accuracy for group of sire to cow was the same observed for group of dam to cow, wherein the average accuracies for AFC was 0.4 , for ACP was 0.4 , and for ACI and CI1 were 0.3. The relative selection efficiency for CI1, when AFC was selected, was 1.23, which indicated that under the same selection intensity, selection for $\mathrm{AFC}$ is $23 \%$ more efficient for improving CI1 than is direct selection for CI1. The advantage of selecting AFC is that this parameter can be measured earlier in the animal's life, in comparison with CI1.

The value obtained for the relative selection efficiency for ACI, when ACP was selected, was 1.11. This indicates that selection for ACP would be $11 \%$ more efficient for improving ACI than direct selection for ACI. The relative selection efficiency for CI1, when ACP was selected, was 1.12. This indicates that indirect selection for this trait was $12 \%$ more efficient for improving CI1 than direct selection for CI1. Therefore, selection based on $\mathrm{AFC}$ and $\mathrm{ACP}$ is more efficient for improving greater genetic changes in CI1 and ACI than if direct selection were performed for these latter 2 traits.

\section{Genetic Trends}

The genetic trend for the EBV of W210 (Fig. 1A) was not significant $(b=-0.011 ; P=0.451)$ and may be justified because of the absence of a breeding program for the period studied. Although the genetic trend for the maternal EBV (Fig. 1B) presented a low and favorable regression coefficient, this value was significant $(b=$ $0.031 ; P=0.039)$, which indicates that there were changes in the mean for the maternal EBV over time. This was possibly due to the choice that the producers made with regard to having females that weaned heavier calves.

Ferraz Filho et al. (2002) observed a favorable change in the direct maternal genetic trend for W210 among Tabapuã cattle. However, these authors used only the mean EBV per year in the regression analysis, whereas in the present study, the breeding values of all the animals evaluated were used in the regression analysis. For Nelore cattle, Zuin et al. (2012) and Sousa et al. (2013) observed significant favorable genetic trends for the direct EBV, which may have been due to the longer period over which the genetic breeding program has been implemented for this breed.

The genetic trend observed for AFC (Fig. 2) was significant $(b=0.005 ; P<0.0001)$ and unfavorable, because there was a slight increase in the genetic trend for this trait. However, the changes that occur in AFC over the years are very small (only $0.005 \mathrm{mo} / \mathrm{yr}$ ). Laureano et al. (2011) observed stability in the genetic trend for AFC between the years 1985 and 1995 and a decrease of $-3.024 \mathrm{~d} / \mathrm{yr}$ over the period between 1996 and 2006 for Nelore cattle. The authors suggested that the practice of exposing young females to bulls was the reason why AFC improved during the second period studied, thus demonstrating that use of this management strategy can improve AFC performance.

The genetic trends for ACI and CI1, (Fig. 3A and 3B) were significant, with an unfavorable genetic change for ACI $(b=0.127 ; P<0.0001)$ and a favorable 


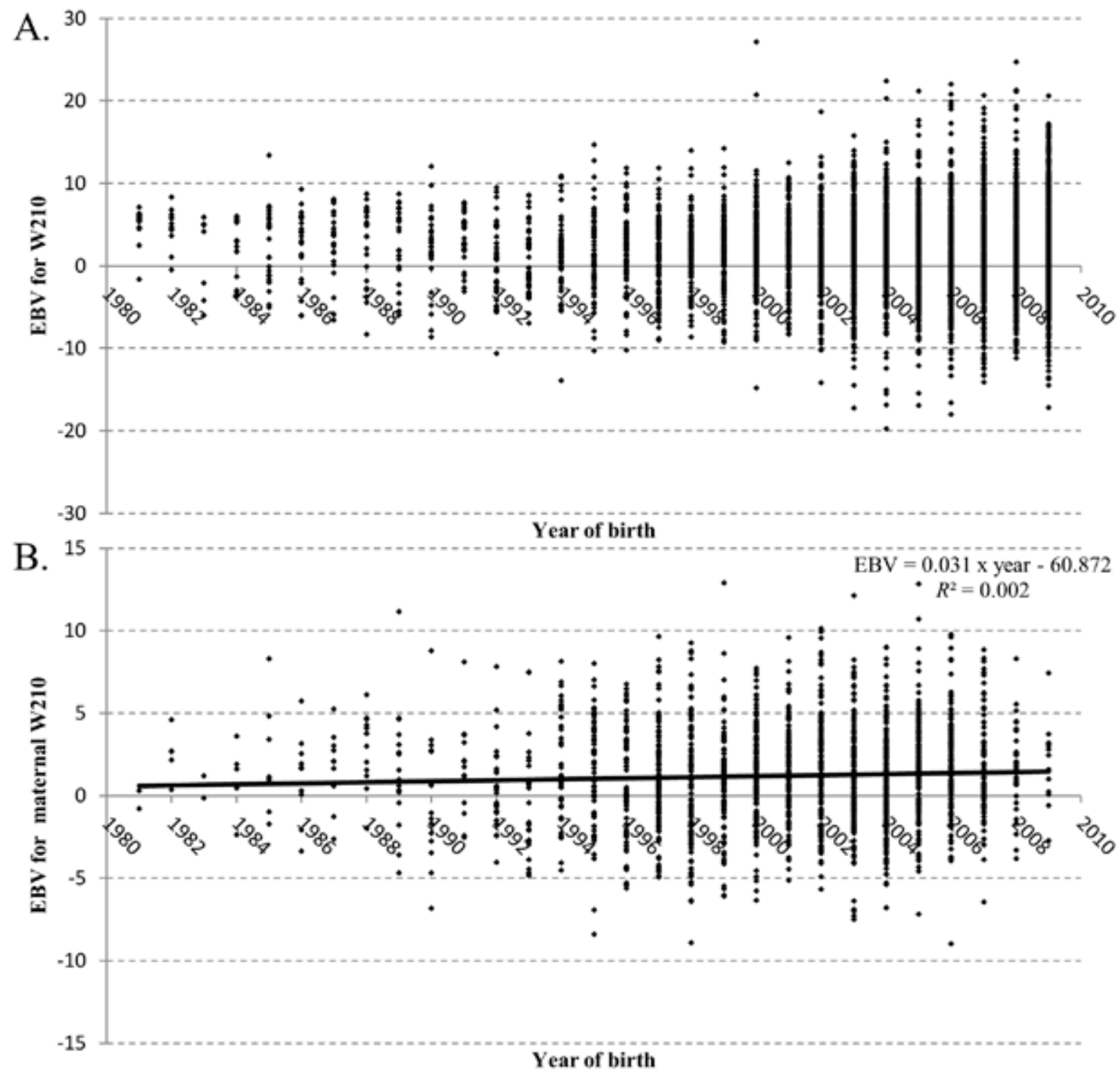

Figure 1. Variation of EBV based on year of birth, from 1981 to 2009, for direct (A) or maternal (B) weaning weight adjusted to $210 \mathrm{~d}$ of age (W210).

change for CI1 $(b=-0.152 ; P=0.002)$. Small modifications can be observed over the years for both traits. Vergara et al. (2009) observed that the genetic trends for the first and second calving intervals were significant in a multibreed population of beef cattle. However, these authors obtained a regression coefficient that was close to 0 and, as in the present study, observed a small decrease in the genetic trend for these traits over the years studied. This demonstrates the importance of the environment to these traits. Moreover, because these traits present low heritability, it is expected that there will not be any great genetic change over the years.

The genetic trend for ACP (Fig. 4) was significant $(b=-0.041 ; P=0.0007)$ and unfavorable over the years. As with the other studied traits, the alteration of this trait over the years was very small and slow. Grossi et al. (2008) observed a favorable genetic trend for ACP in a population of Nelore cattle, whereas
Chud et al. (2014), for the same breed, did not observe any significant genetic trend for this trait.

The genetic trends observed for the traits studied presented genetic changes close to 0 , despite being significant $(P<0.05)$ for AFC, ACI, CI1, and ACP. These results may have been a consequence of the absence of a genetic breeding program for the Tabapuã breed up to 2008.

The heritability for W210 indicates that this trait has sufficient genetic variability to respond to genetic selection. The relative selection efficiency showed that AFC and ACP should be considered in breeding programs because they presented the greatest heritability estimates in relation to the remaining traits and favorable genetic association with these traits.

Due to recent the breeding program implantation for the Tabapuã breed, it becomes necessary to consider selection criteria that attain the breeding goal of improve productive and reproductive performance. The MGT in- 


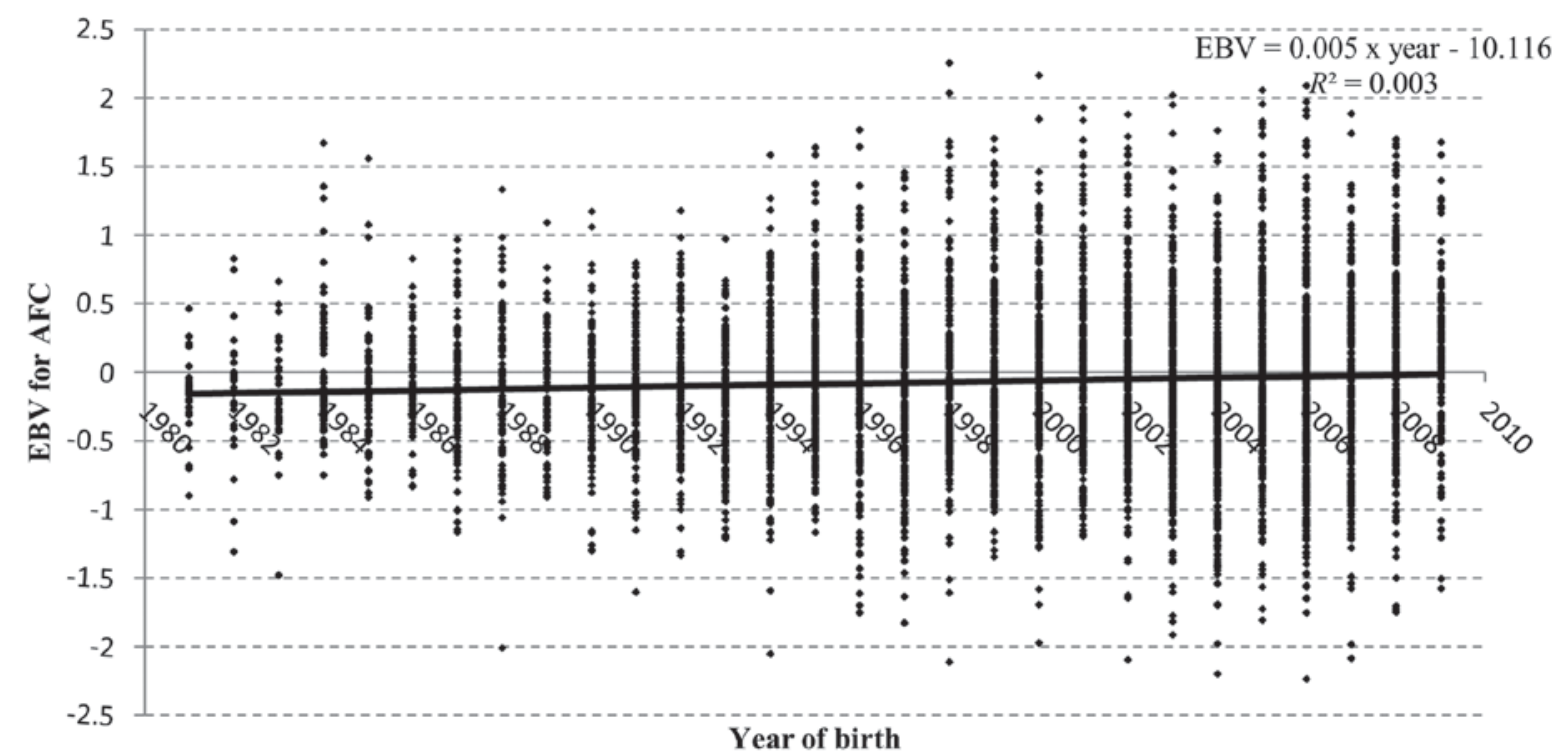

Figure 2. Linear regression of EBV, based on year of birth, from 1981 to 2009, for age at first calving (AFC).

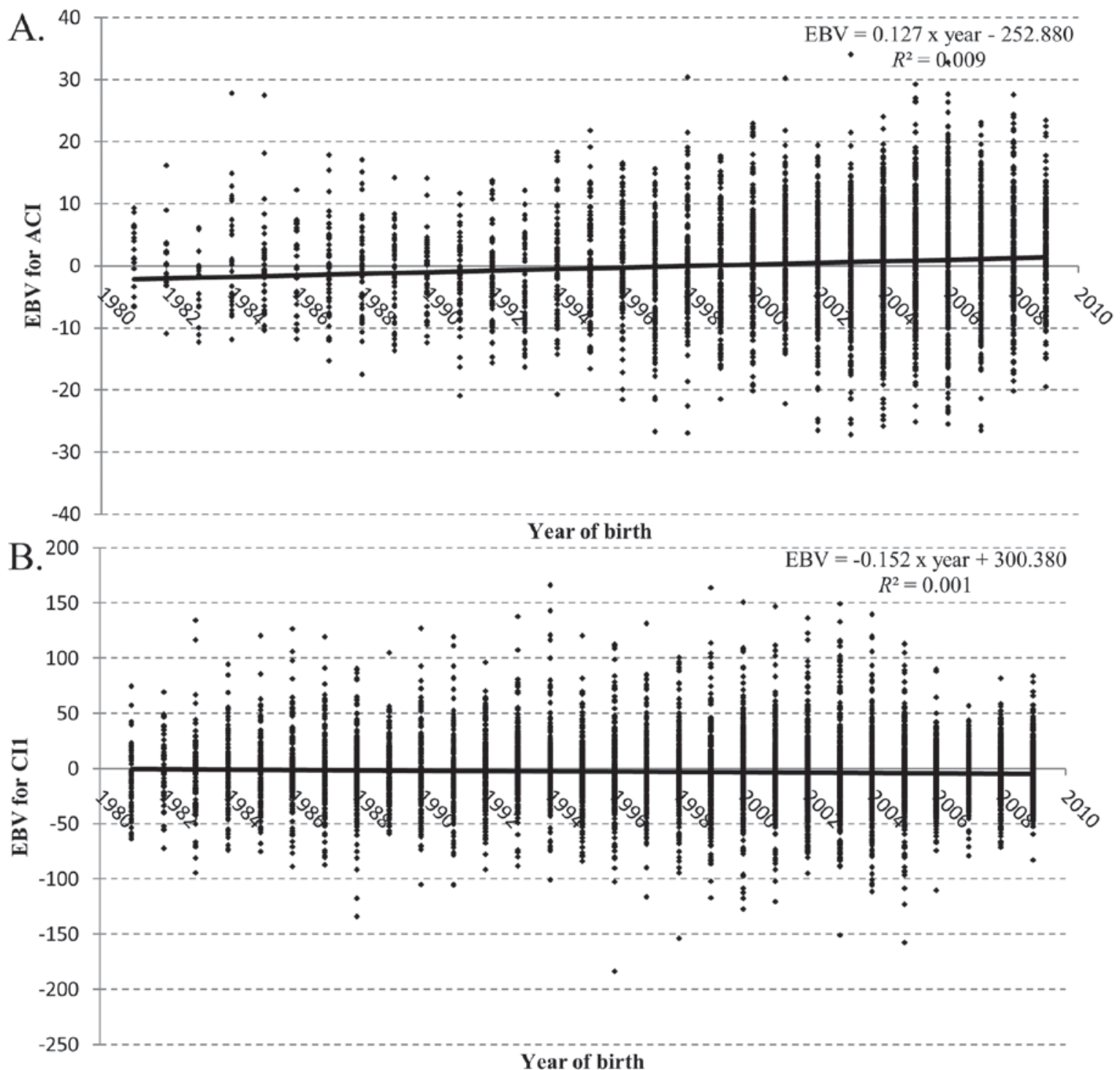

Figure 3. Linear regression of EBV, based on year of birth, from 1981 to 2009, for average calving interval (ACI; A) and for first calving interval (CI1; B). 


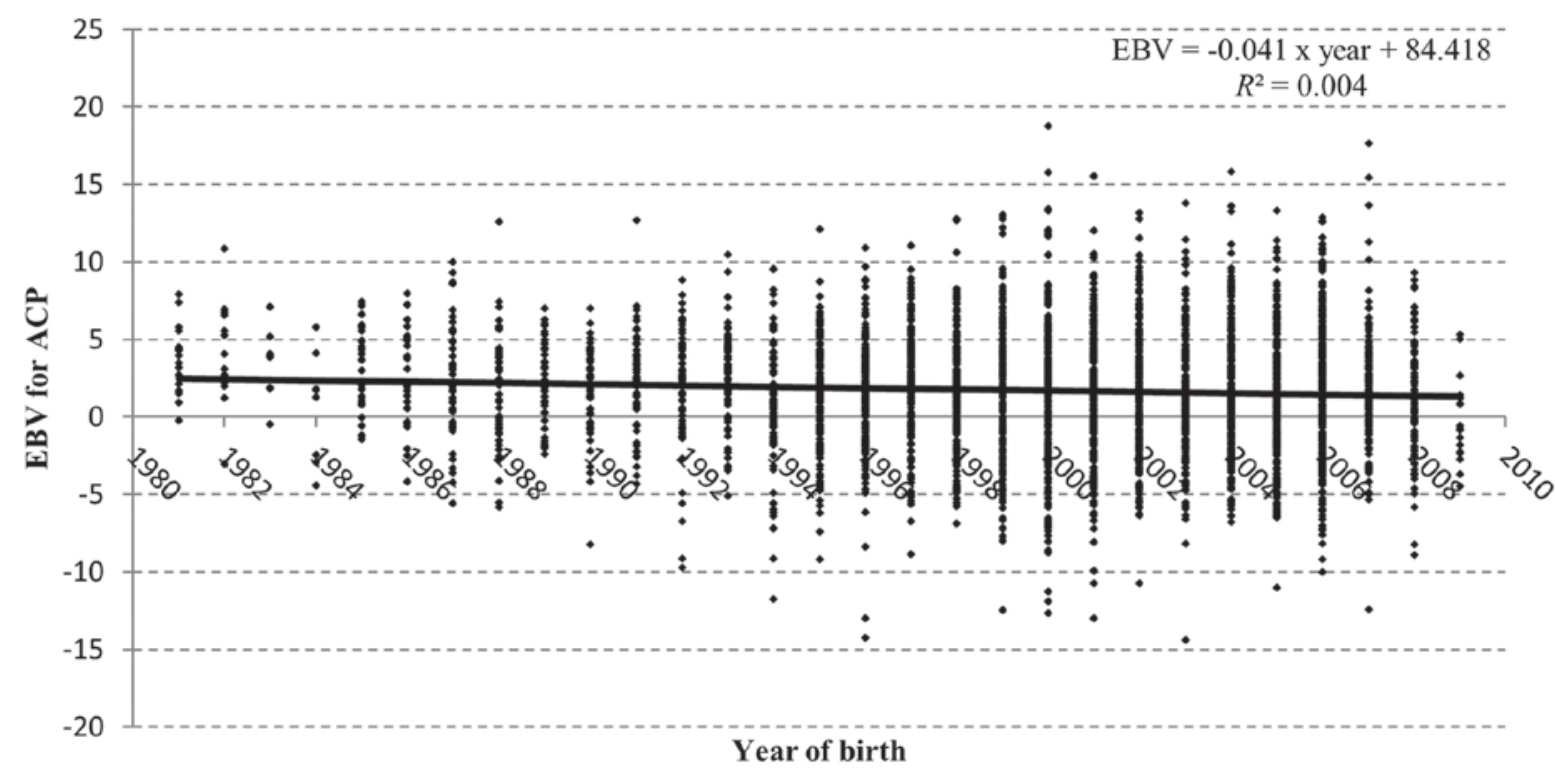

Figure 4. Linear regression of EBV, based on year of birth, from 1981 to 2009, for accumulated productivity (ACP).

dex suggested from PMGRT includes the genetic evaluation for the following traits in a weighted manner (between parentheses): maternal genetic effect on weight at $120 \mathrm{~d}$ of age (0.10), direct genetic effect on weight at $120 \mathrm{~d}$ of age (0.20), weight at $365 \mathrm{~d}$ of age $(0.20)$, weight at $450 \mathrm{~d}$ of age (0.20), scrotal circumference at $365 \mathrm{~d}$ of age (0.05), scrotal circumference at $450 \mathrm{~d}$ of age $(0.05)$, and AFC $(0.20)$. This index could be used by Tabapuã producers, because it has different BW measured earlier in an animal's life as selection criteria and the BW have high and positive genetic correlation with weaning weight (Ferraz Filho et al., 2002), not requiring the direct inclusion of weaning weight in the index. The total weighting for the productive traits correspond to 0.70 , which attends the need of improve productive performance.

Moreover, the MGT index has weighting for scrotal circumference and a high weighting for AFC, which can improve reproductive performance. However, due to low heritability estimates for reproductive traits, it becomes interesting to include other direct or indirect selection criteria that can improve reproductive performance. The high weighting for AFC proved to be interesting once that is measured before the CI1 and showed greater relative selection efficiency compared with direct selection for CI1.

The results showed that the ACP could be included in the MGT index to assist the reproductive performance because ACP presented greater relative selection efficiency for the calving intervals and higher heritability estimate compared with AFC. Furthermore, the weaning weight is considered to calculate ACP, which can be another way to include this BW indirectly in selection process, assisting in productive performance besides reproductive performance. Therefore, increases in genetic gains will be expected over the years for the reproductive and productive traits evaluated in this study if ACP is included in the MGT as selection criterion.

\section{LITERATURE CITED}

Aby, B. A., L. Aass, E. Sehestedb, and O. Vangen. 2012. Effects of changes in external production conditions on economic values of traits in Continental and British beef cattle breeds. Livest. Sci. 150:80-93. doi:10.1016/j.livsci.2012.08.002.

Associação Nacional de Criadores e Pesquisadores (ANCP). 2014. Programa de Melhoramento Genético da Raça Tabapuã. http://www.ancp.org.br/pagina/31/tabapua\#.U1unA_ldWAk. (Accessed 21 April 2014.)

Azevêdo, D. M. M. R., R. Martins Filho, R. N. B. Lôbo, R. B. Lôbo, A. A. A. N. Moura, E. C. Pimenta Filho, and C. H. M. Malhado. 2005. Accumulated productivity of Nellore cows raised in north and northeast of Brazil. R. Bras. Zootec. 34:54-59. doi:10.1590/S1516-35982005000100007.

Barrozo, D., M. E. Buzanskas, J. A. Oliveira, D. P. Munari, H. H. R. Neves, and S. A. Queiroz. 2012. Genetic parameters and environmental effects on temperament score and reproductive traits of Nellore cattle. Animal 6:36-40. doi:10.1017/S1751731111001169.

Berry, D. P., and R. D. Evans. 2014. Genetics of reproductive performance in seasonal calving beef cows and its association with performance traits. J. Anim. Sci. 92:1412-1422. doi:10.2527/jas.2013-6723.

Boligon, A. A., and L. G. Albuquerque. 2011. Genetic parameters and relationships of heifer pregnancy and age at first calving with weight gain, yearling and mature weight in Nelore cattle. Livest. Sci. 141:12-16. doi:10.1016/j.livsci.2011.04.009.

Boligon, A. A., L. G. Albuquerque, M. E. Z. Mercadante, and R. B. Lôbo. 2010. Study of relations among age at first calving, average weight gains and weights from weaning to maturity in Nellore cattle. R. Bras. Zootec. 39:746-751. doi:10.1590/ S1516-35982010000400007. 
Boligon, A. A., F. Baldi, and L. G. Albuquerque. 2012. Genetic correlations between heifer subsequent rebreeding and age at first calving and growth traits in Nellore cattle by Bayesian inference. Genet. Mol. Res. 11:4516-4524. doi:10.4238/2012.October.17.2.

Bourdon, R. M. 2000. Correlated response to selection. In: Understanding animal breeding. Prentice Hall, Upper Saddle River, NJ. p. 275-292.

Buzanskas, M. E., D. A. Grossi, F. Baldi, D. Barrozo, L. O. C. Silva, R. A. A. Torres Júnior, D. P. Munari, and M. M. Alencar. 2010. Genetic associations between stayability and reproductive and growth traits in Canchim beef cattle. Livest. Sci. 132:107-112. doi:10.1016/j.livsci.2010.05.008.

Campos, B. M. 2013. Análise genética e comparação de modelos por inferência bayesiana e frequentista em características de crescimento de bovinos da raça Tabapuã do estado da Bahia. (In Portuguese.) MSc Diss., Universidade Estadual do Sudoeste da Bahia, Itapetinga, Brazil.

Chud, T. C. S., S. L. Caetano, M. E. Buzanskas, D. A. Grossi, D. G. F. Guidolin, G. B. Nascimento, J. O. Rosa, R. B. Lôbo, and D. P. Munari. 2014. Genetic analysis for gestation length, birth weight, weaning weight, and accumulated productivity in Nellore beef cattle. Livest. Sci. 170:16-21. doi:10.1016/j.livsci.2014.09.024.

Cunningham, J. G. 2007. Reproductive cycles. In: Textbook of veterinary physiology. Saunders Elsevier, St. Louis, MO. p. 466-498.

Dobson, A. J. 1990. Inference. In: An introduction to generalized linear models. Chapman and Hall, Melbourne, Australia. p. 75-89.

Eler, J. P., A. B. Bignardi, J. B. S. Ferraz, and M. I. Santana Jr. 2014. Genetic relationships among traits related to reproduction and growth of Nelore females. Theriogenology 82:708714. doi:10.1016/j.theriogenology.2014.06.001.

Faria, C. U., C. U. Magnabosco, A. Reyes, R. B. Lôbo, L. A. F. Bezerra, and R. D. Sainz. 2007. Bayesian inference on field data for genetic parameters for some reproductive and related traits of Nellore cattle (Bos indicus). Genet. Mol. Biol. 30:343-348.

Ferraz Filho, P. B., A. A. Ramos, L. O. C. Silva, J. C. Souza, and M. M. Alencar. 2002. Heritability and genetic, phenotypic and environmental correlations for weight at different ages in bovines of Tabapuã breed. Arch. Vet. Sci. 7:65-69.

Grossi, D. A., O. G. Frizzas, C. C. P. Paz, L. A. F. Bezerra, R. B. Lôbo, J. A. Oliveira, and D. P. Munari. 2008. Genetic associations between accumulated productivity, and reproductive and growth traits in Nelore cattle. Livest. Sci. 117:139-146. doi:10.1016/j.livsci.2007.12.007.

Grossi, D. A., G. C. Venturini, C. C. P. Paz, L. A. F. Bezerra, R. B. Lôbo, J. A. Oliveira, and D. P. Munari. 2009. Genetic associations between age at first calving and heifer body weight and scrotal circumference in Nelore cattle. J. Anim. Breed. Genet. 126:387-393. doi:10.1111/j.1439-0388.2008.00791.x.

Guimarães, L. B., P. B. Ferraz Filho, J. C. Souza, and L. O. C. Silva. 2003. Genetic and environmental aspects in regard to the pre and post calfing in Tabapuã bovines at the Western São Paulo Paraná cattle raising region. Arch. Vet. Sci. 8:109-119.

Gutiérrez, J. P., I. Alvarez, I. Fernández, L. J. Royo, J. Díez, and F. Goyache. 2002. Genetic relationships between calving date, calving interval, age at first calving and type traits in beef cattle. Livest. Prod. Sci. 78:215-222. doi:10.1016/S0301-6226(02)00100-8.

Gutiérrez, J. P., F. Goyache, I. Fernández, I. Alvarez, and L. J. Royo. 2007. Genetic relationships among calving ease, calving interval, birth weight, and weaning weight in the Asturiana de los Valles beef cattle breed. J. Anim. Sci. 85:6975. doi:10.2527/jas.2006-168.
Henao, G., M. Olivera-Ángel, and J. G. Maldonado-Estrada. 2000. Follicular dynamics during postpartum anestrus and the first estrous cycle in suckled or non-suckled Brahman (Bos indicus) cows. Anim. Reprod. Sci. 63:127-136. doi:10.1016/ S0378-4320(00)00173-1.

Laureano, M. M. M., A. A. Boligon, R. B. Costa, S. Forni, J. L. P. Severo, and L. G. Albuquerque. 2011. Estimates of heritability and genetic trends for growth and reproduction traits in Nelore cattle. Arq. Bras. Med. Vet. Zootec. 63:143-152. doi:10.1590/S0102-09352011000100022.

Lôbo, R. B., L. A. F. Bezerra, H. N. Oliveira, A. V. Garnero, E. B. Schwengber, and C. R. Marcondes. 2000. Avaliação genética de animais jovens, touros e matrizes. (In Portuguese.) Sumário, Ribeirão Preto, Brazil.

Meyer, K. 2007. WOMBAT-A tool for mixed model analyses in quantitative genetics by restricted maximum likelihood (REML). J. Zhejiang Univ. Sci. B 8:815-821. doi:10.1631/jzus.2007.B0815.

Paneto, J. C. C., J. B. S. Ferraz, J. C. C. Balieiro, J. F. F. Bittar, M. B. D. Ferreira, M. B. Leite, G. K. F. Merighe, and F. V. Meirelles. 2008. Bos indicus or Bos taurus mitochondrial DNA - Comparison of productive and reproductive breeding values in a Guzerat dairy herd. Genet. Mol. Res. 7:592-602. doi:10.4238/vol7-3gmr449.

Panetto, J. C. C., J. P. Gutiérrez, J. B. S. Ferraz, D. G. Cunha, and B. L. Golden. 2010. Assessment of inbreeding depression in a Guzerat dairy herd: Effects of individual increase in inbreeding coefficients on production and reproduction. J. Dairy Sci. 93:4902-4912. doi:10.3168/jds.2010-3197.

Pereira, J. C. C., S. H. A. Ribeiro, M. A. Silva, J. A. G. Bergmann, and M. D. Costa. 2005. Genetics analysis of growth and reproduction traits in a herd of Tabapuã females. Arq. Bras. Med. Vet. Zootec. 57:231-236.

Renquist, B. J., J. W. Oltjen, R. D. Sainz, and C. C. Calvert. 2006. Relationship between body condition score and production of multiparous beef cows. Livest. Sci. 104:147-155. doi:10.1016/j.livsci.2006.04.004.

Ribeiro, S. H. A., J. C. C. Pereira, R. S. Verneque, M. A. Silva, J. A. G. Bergmann, and F. S. Marques. 2007. A genetic-quantitative study of growth traits in Tabapuã cattle. Arq. Bras. Med. Vet. Zootec. 59:473-480. doi:10.1590/S0102-09352007000200030.

Rosa, A. N. 1999. Variabilidade fenotípica e genética do peso adulto e da produtividade acumulada de matrizes em rebanhos de seleção da raça Nelore no Brasil. (In Portuguese) PhD Diss., Universidade de São Paulo, Ribeirão Preto, Brazil

Roso, V. M., and F. S. Schenkel. 2006. AMC - A computer program to assess the degree of connectedness among contemporary groups. In: World Congr. Genet. Appl. Livest. Prod, Belo Horizonte, Brazil. http://www.cabi.org/cabdirect/ FullTextPDF/2006/20063170108.pdf(Accessed 15 April 2014.)

Sakaguti, E. S., M. A. Silva, R. L. Quaas, E. N. Martins, P. S. Lopes, and L. O. C. Silva. 2003. Growth evaluation of young Tabapuã beef cattle by covariance functions analyses. R. Bras. Zootec. 32:864-874. doi:10.1590/S1516-35982003000400011.

Santana Júnior, M. L., P. S. Lopes, R. S. Verneque, R. J. Pereira, M. R. Lagrotta, and M. G. C. D. Peixoto. 2010. Genetic parameters for reproductive traits of dairy Gyr breed males and females. R. Bras. Zootec. 39:1717-1722. doi:10.1590/S1516-35982010000800013.

Schwengber, E. B., L. A. F. Bezerra, and R. B. Lôbo. 2001 Accumulated productivity as selection criteria in Nellore breed females. Cienc. Rural 31:483-486. doi:10.1590/ S0103-84782001000300020. 
Segura-Correa, J. C., R. C. Chin-Colli, J. G. Magaña-Monforte, and R. Núñez-Domínguez. 2012. Genetic parameters for birth weight, weaning weight and age at first calving in Brown Swiss cattle in Mexico. Trop. Anim. Health Prod. 44:337-341. doi:10.1007/s11250-011-0026-8.

Silva Filho, E., T. T. G. Almeida, P. H. Souza, and A. C. Pereira Junior. 2013. Herdability of the weaning weight in Brangus and Tabapuã cattle breeds in the pre-Amazon region. Indian J. Appl. Res. 3:470-471. doi:10.15373/2249555X/NOV2013/151.

Silva Filho, E., M. H. Silva, J. E. G. Campelo, M. L. Harada, and M. R. DeRosia. 2012. Genetic characterization of a bovine breed (Tabapua) under artificial selection located in the Amazon region. Am. J. Anim. Vet. Sci. 4:226-232. doi:10.3844/ajavssp.2012.226.232.

Sousa, M. F. A., R. Martins Filho, S. C. Sousa Júnior, W. J. L. Fonsceca, G. G. T. Sousa, C. S. M. Luz, C. P. Barros Junior, A. C. Araujo, and J. I. M. Araújo. 2013. Estimation of phenotypic and genetic parameters and genetic trend of weights in the weaning phase (P205), weight at one year (P365), the yearling (P505) in Nellore cattle in the Northern region and Under-Region Middle-North of Brazil. J. Agric. Sci. 5:37-50..
Ventura, R. V., M. A. Silva, T. H. Medeiros, N. L. Dionello, F. E. Madalena, A. B. Fridrich, B. D. Valente, G. G. Santos, L. S. Freitas, R. R. Wenceslau, V. P. S. Felipe, and G. S. S. Corrêa. 2012. Use of artificial neural networks in breeding values prediction for weight at 205 days in Tabapuã beef cattle. Arq. Bras. Med. Vet. Zootec. 64:411-418. doi:10.1590/S0102-09352012000200022.

Vergara, O. D., M. A. Elzo, and M. F. Cerón-Muñoz. 2009. Genetic parameters and genetic trends for age at first calving and calving interval in an Angus-Blanco Orejinegro-Zebu multibreed cattle population in Colombia. Livest. Sci. 126:318322. doi:10.1016/j.livsci.2009.07.009.

Yokoo, M. J., C. U. Magnabosco, G. J. M. Rosa, R. B. Lôbo, and L. G. Albuquerque. 2012. Reproductive traits and their associations with other economically important traits in Nelore. Arq. Bras. Med. Vet. Zootec. 64:91-100. doi:10.1590/S010209352012000100014.

Zuin, R. G., M. E. Buzanskas, S. L. Caetano, G. C. Venturini, D. G. F. Guidolin, D. A. Grossi, T. C. S. Chud, C. C. P. Paz, R. B. Lôbo, and D. P. Munari. 2012. Genetic analysis on growth and carcass traits in Nelore cattle. Meat Sci. 91:352-357. doi:10.1016/j.meatsci.2012.02.018. 